\title{
Chromosome $3 p$ allele loss in early invasive breast cancer: detailed mapping and association with clinicopathological features
}

\author{
A Martinez, R A Walker, J A Shaw, S J Dearing, E R Maher, F Latif
}

\begin{abstract}
Aims-Chromosome 3p allele loss is a frequent event in many common sporadic cancers including lung, breast, kidney, ovarian, and head and neck cancer. To analyse the extent and frequency of $3 p$ allelic losses in $\mathrm{T} 1 \mathrm{~N} 0$ and $\mathrm{T} 1 \mathrm{~N} 1$ invasive sporadic breast cancer, 19 microsatellite markers spread along $3 \mathbf{p}$ were analysed in 40 such breast carcinomas with known clinicopathological parameters.

Methods-Loss of heterozygosity analysis was carried out using $3 p$ microsatellite markers that were non-randomly distributed and chosen to represent regions that show hemizygous and/or homozygous losses in lung cancer (lung cancer tumour suppressor gene region 1 ( LCTSGR1) at $3 p 21.3$ and LCTSGR2 at 3p12), and regions demonstrating suppression of tumorigenicity in breast, kidney, lung, and ovarian cancer.
\end{abstract}

Results-Allelic loss was seen at one or more loci in 22 of these clinically early stage sporadic breast tumours, but none had complete $3 p$ allele loss. Several regions with non-overlapping deletions were defined, namely: (1) 18 tumours showed loss at 3p21-22, a physical distance of $12 \mathrm{Mb}$; (2) 11 tumours showed loss at $3 \mathrm{p} 12$ within a physical distance of $1 \mathrm{Mb}$, this region is contained within LCTSGR2; (3) six tumours showed loss at 3p25-24, including the von Hippel-Lindau (VHL) locus; (4) five tumours showed loss at $3 p 14.2$, including the fragile histidine triad (FHIT) locus.

Conclusions-This is the largest study to date defining the extent and range of $3 p$ allelic losses in early stage invasive breast cancer and the results indicate that region 3p21-22 containing LCTSGR1 and a region at $3 p 12$ within LCTSGR2 are the most frequent sites of $3 p$ allelic loss in these breast carcinomas. This suggests that tumour suppressor genes located in these regions may play important roles in the development of breast cancer. There was an association between increasing $3 p$ allelic loss and increasing tumour grade and loss of progesterone $(p=0.0098)$ and oestrogen $(p=0.0472)$ receptor expression, indicating a link between $3 p$ allelic loss and the regulation of differentiation. (F Clin Pathol: Mol Pathol 2001;54:300-306)

Keywords: chromosome 3p; tumour suppressor genes; early invasive breast cancer
In the Western world breast cancer is the most prevalent malignancy in women. The incidence of breast cancer is rising and it is estimated that one in 10 women will develop breast cancer during her life time. ${ }^{1}$ An understanding of the genetic alterations involved in breast cancer development and progression may aid earlier detection and management.

Certain alterations, such as amplification of the oncogene ERBB2, can be found in a proportion of both in situ and invasive breast cancers, as can mutations of the tumour suppressor gene (TSG) p53 at 17q13, suggesting that they could play a role in the development of these tumours. Alterations to other oncogenes and TSGs, such as MYC and $\mathrm{RB} 1$, are associated with more advanced disease. ${ }^{2}$ Loss of heterozygosity ( $\left.\mathrm{LOH}\right)$ on chromosomes 1, 3p, 6q, 7q, 8p, 11p, 13q, 17p, $17 \mathrm{q}, 18 \mathrm{q}$, and $22 \mathrm{q}$ has been reported in breast carcinomas and other tumours (reviewed in Bieche and Lidereau ${ }^{3}$ and Schwab ${ }^{4}$ ), indicating a role for TSGs located in these regions in the development and progression of different cancers. For familial breast cancer, two major genes have been isolated, BRCA1 at 17q21 and BRCA2 at 13q12-13 (reviewed in Buchholz and colleagues ${ }^{5}$ and Yang and Lippman ${ }^{6}$ ), and a third locus (at least) is also thought to exist. ${ }^{78}$ BRCA1 and BRCA2 do not show inactivating mutations in sporadic breast tumours, and their role in sporadic cancers is not known.

By means of hemizygosity and homozygosity mapping, cytogenetic analysis, and functional studies, distinct regions on $3 \mathrm{p}(3 \mathrm{p} 25-26,3 \mathrm{p}$ $21-22,3 p 14.2$, and $3 p 12$ ) have been shown to be important for the development of several common sporadic cancers including lung, breast, kidney, ovarian, cervical, and head and neck cancer (reviewed in Kok and colleagues $\left.^{9}\right) .^{10-13}$ The region $3 \mathrm{p} 25$ contains the von Hippel-Lindau (VHL) TSG, ${ }^{14}{ }^{15}$ which is inactivated in patients with von Hippel-Lindau disease and approximately $70 \%$ of sporadic clear cell renal carcinomas. ${ }^{16-19}$ However, mutations of VHL are rare in other common sporadic cancers that show $3 p$ allele loss, such as lung and gonadal tumours. ${ }^{17} 20$ The fragile histidine triad (FHIT) gene at 3p14.2 undergoes homozygous deletions and alterations in its mRNA in many sporadic cancers (reviewed in Huebner and colleagues ${ }^{21}$ and Sozzi and colleagues ${ }^{22}$ ). High amounts of allele loss at the FHIT locus have been found in low grade ductal carcinoma in situ of the breast and the well differentiated tubular carcinomas, ${ }^{23}$ suggesting that alterations at the FHIT locus may be 
important in development of low grade breast cancer.

We have previously reported homozygous $3 p$ deletions in sporadic breast cancers. The region at $3 \mathrm{p} 21.3$ (lung cancer tumour suppressor gene region 1; LCTSGR1) is defined by four overlapping homozygous deletions in three small cell lung cancer cell lines and one primary breast tumour. ${ }^{24-27}$ The 3 p 12 region (LCTSGR2) contains two overlapping homozygous deletions in small cell lung cancer cell lines and one breast tumour cell line. ${ }^{28}$ Several genes have been isolated from LCTSGR1 and one from LCTSGR2, but so far none shows frequent inactivating mutations in lung cancer. ${ }^{27}{ }^{28}$ Recently, a small study $(\mathrm{n}=8)$ demonstrated $3 p$ allelic loss in benign breast lesions preceding invasive breast cancer. ${ }^{29}$ Another study demonstrated $3 \mathrm{p}$ loss in normal tissue adjacent to breast carcinomas, the most frequent loss being $3 \mathrm{p} 22-25 .^{30}$ However, only a low frequency of $3 p$ loss has been found in comparative genomic hybridisation studies of ductal carcinoma in situ. ${ }^{31}$

We have analysed $3 p$ allelic losses in T1N0 and $\mathrm{T} 1 \mathrm{~N} 1$ sporadic invasive breast carcinomas to determine their extent and frequency. We focused on specific $3 p$ regions, (3p25-26, $3 \mathrm{p} 21-22$, 3p14.2, and $3 \mathrm{p} 12$ ) implicated in tumorigenesis in breast and other cancers. We found $3 p$ loss in most of these breast tumours, and the two most frequently lost regions on $3 p$ included LCTSGR1 and LCTSGR2. In addition, a trend was found between $3 p$ allelic loss, higher tumour grade, and loss of oestrogen and progesterone receptors (ER and PR, respectively), suggesting that there are genes on $3 p$ that are associated with differentiation and that their loss results in breast cancers with more aggressive features.

\section{Materials and methods}

PATIENTS AND SAMPLES

A total of 40 invasive breast carcinomas (39 infiltrating ductal carcinomas and one infiltrating lobular carcinoma) were studied. Twenty five were detected by mammographic screening and the others had presented symptomatically. Carcinomas were excised at Glenfield Hospital NHS Trust between July 1995 and July 1997. Tumours of $20 \mathrm{~mm}$ or less in maximum diameter were examined (range, 10 $20 \mathrm{~mm}$; mean, 17), and 15 had nodal metastases ( $\mathrm{T} 1 \mathrm{~N} 0$ or $\mathrm{T} 1 \mathrm{~N} 1$, no more than three lymph nodes involved in positive cases). None of the tumours was from a woman with a known family history of breast or other cancers.

All tissues were fixed in $4 \%$ formaldehyde in saline for 18-36 hours. After slicing, selected blocks were processed through graded alcohols and xylene to paraffin wax.

The carcinomas were reported according to the Royal College of Pathologists' working party guidelines (1990). Infiltrating ductal carcinomas were graded using the modified Bloom and Richardson system. ${ }^{32}$ All tissue histological assessments were performed by RAW.

ER and PR immunohistochemistry was undertaken as described previously. ${ }^{33}$

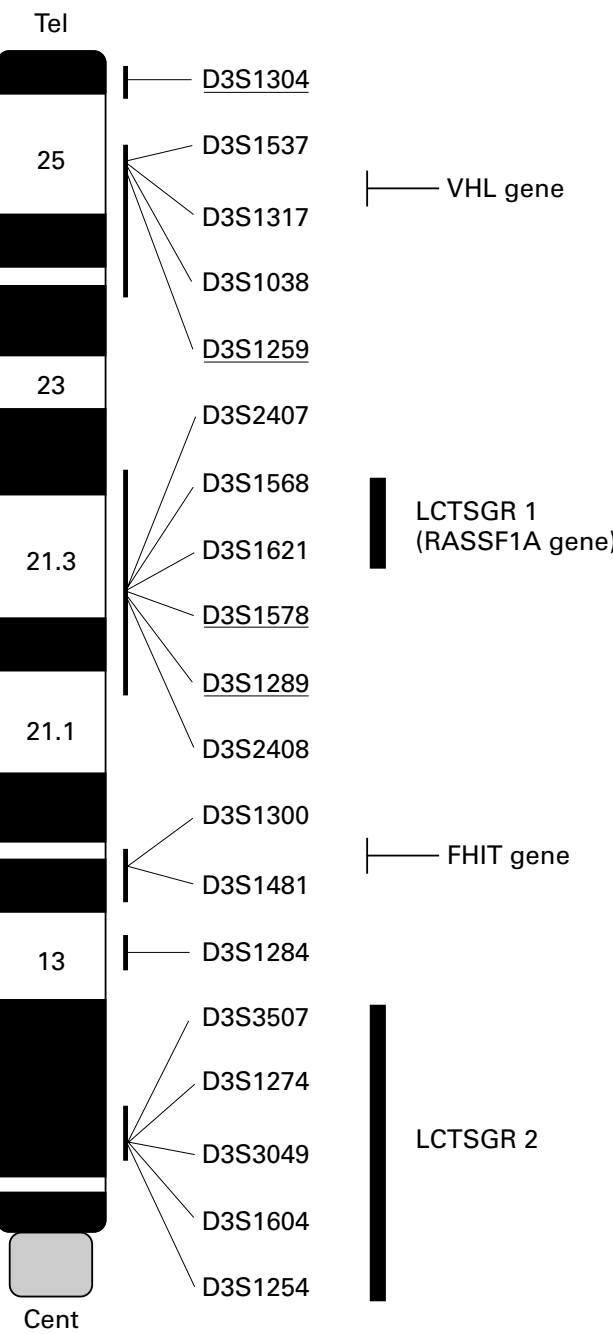

Figure 1 Summary of polymorphic markers and regions of interest on chromosome 3p. Genetic markers are listed in descending order from telomere to centromere according to published maps (UDB) and websites (http://

apollo.uthscsa.edul) and approximate cytogenetic (ideogram) positions. The regions LCTSGR1 and LCTSGR2 implicated in lung cancer development at $3 p 21.3$ and $3 p 12$ are also shown. The underlined markers represent loci shown to be important for suppression of tumorigenicity in an ovarian tumour cell line. ${ }^{1140}$ The positions of the VHL (von Hippel-Lindau), RASSF1A and FHIT (fragile histidine triad) genes are also shown.

DNA EXTRACTION AND MICRODISSECTION FROM PARAFFIN WAX EMBEDDED SECTIONS

Formalin fixed, paraffin wax embedded tissue from breast tumours and non-involved nodes served as the source of tumour and normal DNA, respectively. For each tumour-normal pair, DNA was extracted from $10 \mu \mathrm{m}$ thick paraffin wax embedded sections, as described previously. $^{34}$

MICROSATELLITE REPEAT ANALYSIS

Polymerase chain reaction (PCR) amplification of dinucleotide, trinucleotide, and tetranucleotide microsatellite sequences was carried out. Nineteen markers were selected spanning the regions of interest on $3 \mathrm{p}$. All are available through Genome Database with the exception of new primers for the D3S1621 locus (forward primer, 5'-CCTCACTACTCCTGG AATTG-3'; reverse primer, 5'-CCAAGGAA 
GGGTTTTA CTTA-3'; PCR product size $140 \mathrm{bp}$, annealing temperature $55^{\circ} \mathrm{C}$ ). $\mathrm{LOH}$ analysis was carried out as described previously. ${ }^{11}$ Electrophoresis was carried out for two to four hours at $90 \mathrm{~W}$ constant power to achieve adequate separation of alleles. After drying the gel was exposed to $x$ ray film (Fuji, Tokyo, Japan).

We defined $\mathrm{LOH}$ as a complete absence of, or significantly decreased signal intensity of, one of the constitutional alleles in tumour DNA as determined by visual examination.

STATISTICAL ANALYSIS

Comparisons were made by Fisher's exact test and the $\chi^{2}$ test as appropriate. $p$ Values of $<0.05$ were taken as significant.

\section{Results}

LOH ANALYSIS USING 3P MICROSATELLITE MARKERS

Figure 1 shows the location of the 19 microsatellite markers from $3 p$ used to screen the 40 tumour-normal DNA pairs of breast carcinomas. The markers are non-randomly distributed and were chosen to represent regions showing hemizygous or homozygous losses and regions that show evidence of suppression of tumorigenicity in several common sporadic cancers including lung, breast, kidney, and ovary (fig 1).

Allelic loss of one or more markers at $3 p$ was seen in 22 tumours. None showed loss of every informative marker and 18 tumours showed no loss of informative markers (fig 2). The 22 tumours showing partial losses of $3 p$ markers were analysed to identify regions of minimal overlapping deletions (fig 2). The highest loss
(18 of 38 informative tumours) was seen at 3p21-22, between D3S2407 and D3S2408. This interval includes the region LCTSGR1, represented by microsatellite markers D3S1568 (equivalent to D3S4615) and D3S1621 (equivalent to D3S4623) and the region shown to be functionally important in ovarian cancer development. Within the region $3 \mathrm{p} 21-22$, the highest loss was observed for D3S2408 (13 of 25 informative tumours). The physical distance of this region bounded by D3S2407 and D3S2408 is $12 \mathrm{Mb}$ (according to the unified database; UDB). Within this large region, smaller regions of overlapping allelic loss identified a region between D3S1289 and D3S2408, with a physical distance of $0.65 \mathrm{Mb}$, as the candidate region (tumours 20 and 14 both show loss at 1289 and retention at 2408, whereas tumours 9, 11, and 19 show retention at 1289 and loss at 2408) (figs 2 and 3). Four tumours showed loss only at 3p21-22 and retention of all informative markers at other $3 p$ regions (tumours 17 , 11,19 , and 20; fig 2 ). The next most frequently lost region was at 3p12, within the LCTSGR2 region, which was lost in 11 of 39 informative tumours. The highest 3 p12 loss was seen for D3S1604 (five of 22 informative tumours); the markers D3S3507, D3S1274, D3S3049, and D3S1604 are located within $<1 \mathrm{Mb}$ of each other. Nine tumours showing $\mathrm{LOH}$ at $3 \mathrm{p} 12$ also showed loss of distal markers, the remaining two tumours showing loss at $3 \mathrm{p} 12$ only were not informative for all distal markers. The region at 3p25-24, which includes the VHL locus, was lost in six tumours; however, all of these tumours also showed LOH at $3 \mathrm{p} 21$ and/ or 3 p12/3p14. Five tumours showed LOH at

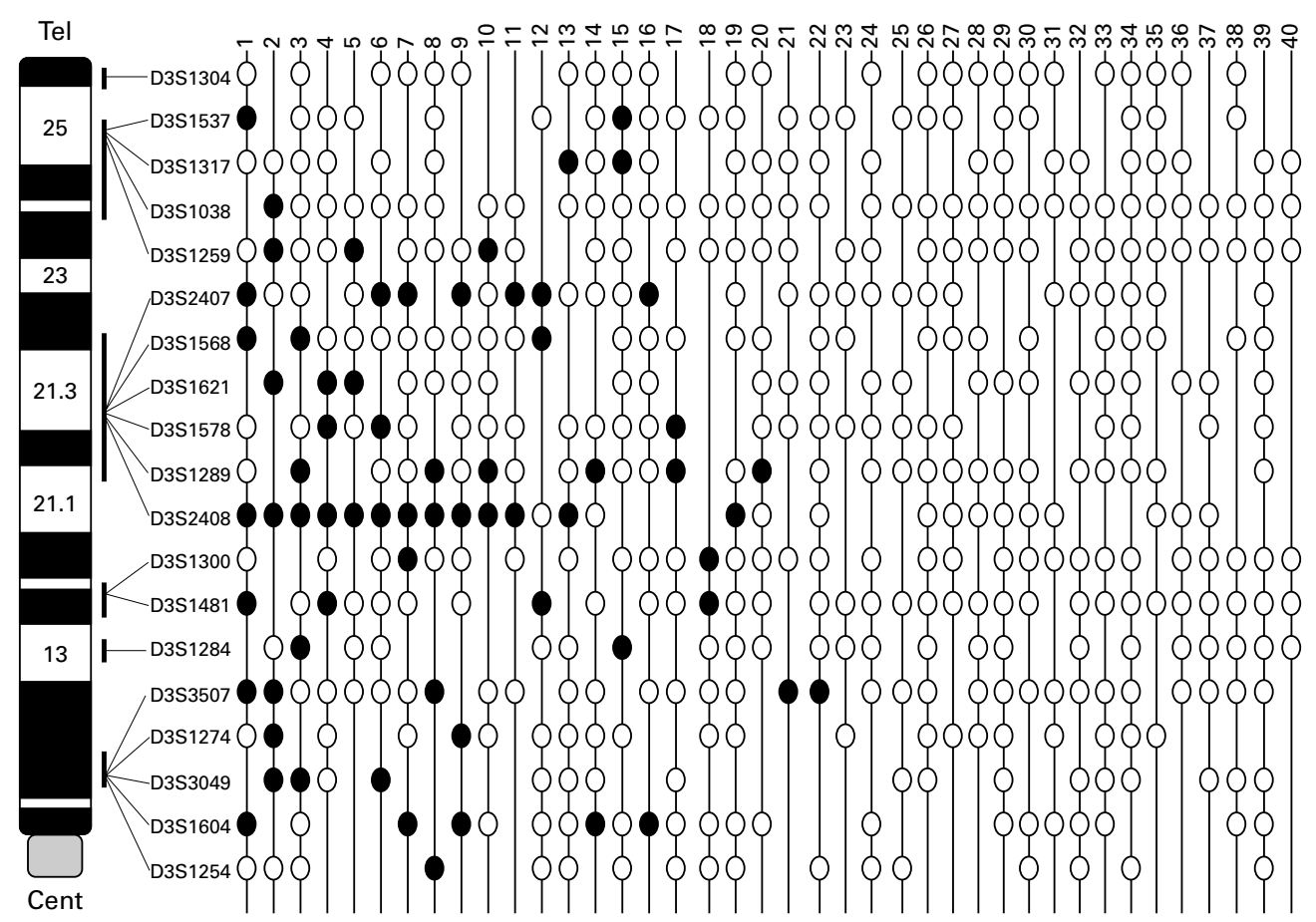

Figure 2 Summary of loss of heterozygosity (LOH) analysis. LOH pattern for all 40 early sporadic breast tumours (39 infiltrating ductal carcinomas and one infiltrating lobular carcinoma) for $3 p$ markers. Each column represents a tumour and each row represents a 3p microsatellite marker listed in descending order from telomere (D3S1304) to centromere (D3S1254). The cases are arranged from left to right in decreasing order of chromosome 3p deletions. Status of each 3p locus is indicated: black circles, loss; white circles, retention; no symbols, uninformative loci. 
the FHIT locus at $3 p 14.2$, but again four of these were accompanied by more distal and or proximal losses, and the one remaining tumour was not informative for all distal and proximal markers.

1

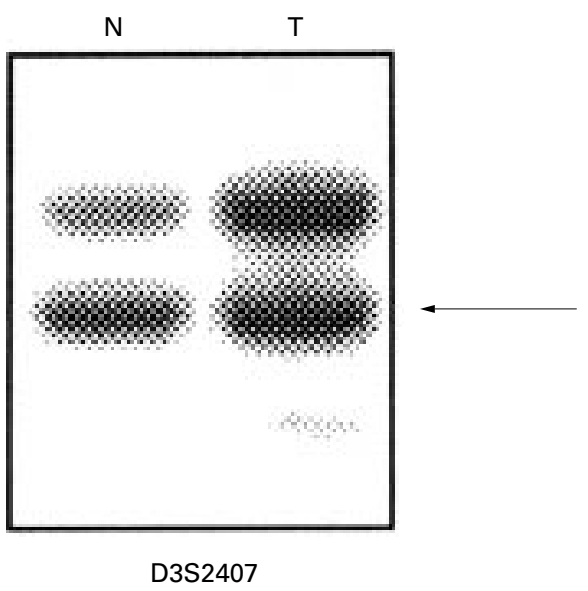

4

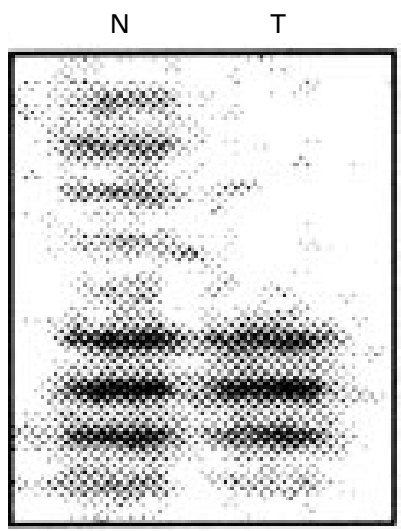

D3S1578

10

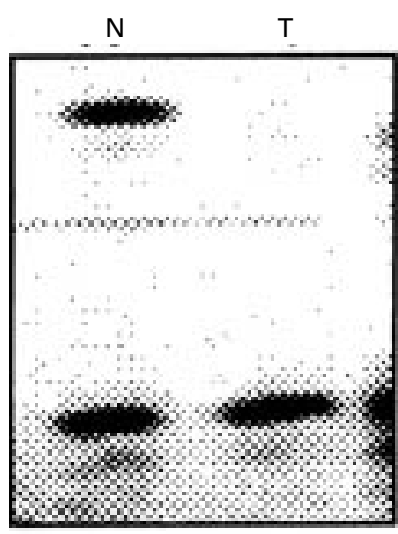

D3S1289

ASSOCIATION WITH CLINICOPATHOLOGICAL PARAMETERS

A trend was seen between increasing $3 \mathrm{p}$ loss and higher tumour grade. Two of the eight grade 1 tumours, 11 of the 21 grade 2 tumours,

5

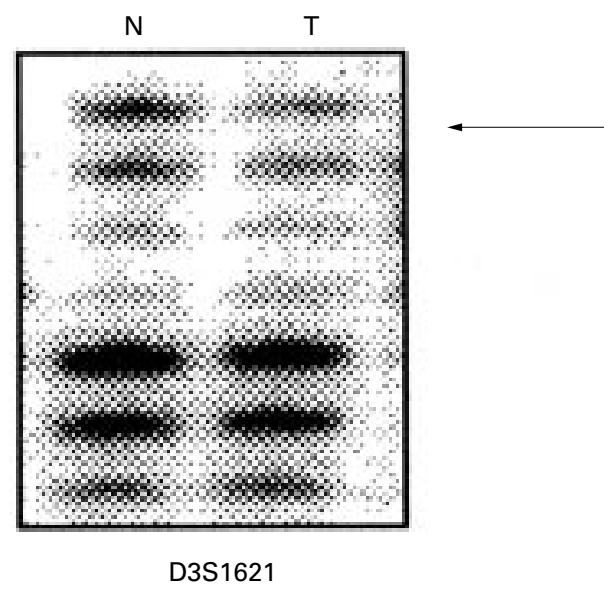

17

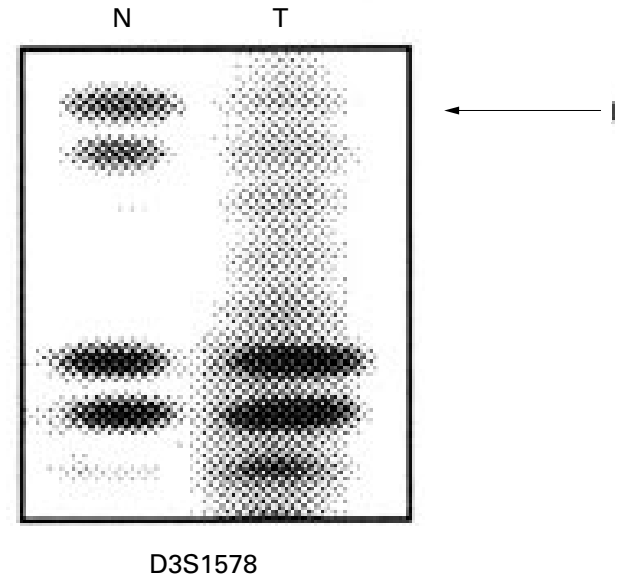

6

$\mathrm{N}$

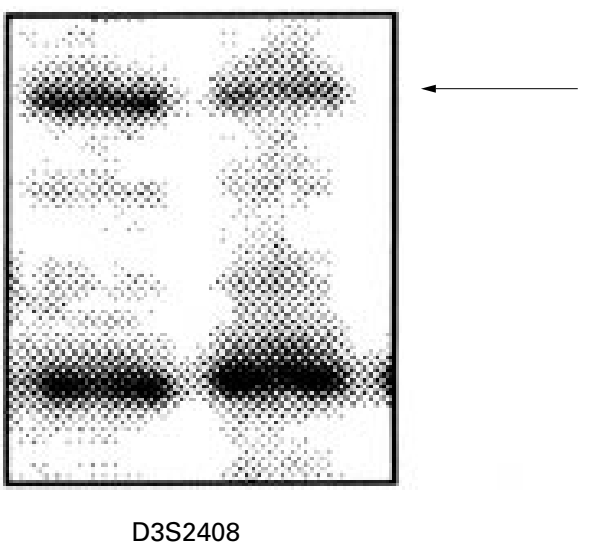

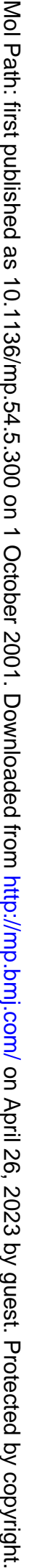

Figure 3 Representative examples of $3 p$ loss of heterozygosity (LOH). Representative autoradiographs showing allelic losses for the markers at 3p21-22 (D3S2407, D3S1621, D3S1578, D3S1289, and D3S2408) in breast tumours. For each autoradiograph the case number is on the top. $N$, normal; T, tumour DNA. Arrowheads represent LOH. 
Table 13 p loss of heterozygosity (LOH), together with grade, lymph node status, progesterone receptor (PR) status, and oestrogen receptor (ER) status

\begin{tabular}{|c|c|c|}
\hline & LOH (number) & Retention (number) \\
\hline & \multicolumn{2}{|c|}{ Any locus on $3 p$} \\
\hline \multicolumn{3}{|l|}{ Grade } \\
\hline 1 & 2 & 6 \\
\hline 2 & 11 & 10 \\
\hline 3 & 8 & 3 \\
\hline \multicolumn{3}{|c|}{ Lymph node status } \\
\hline- & 14 & 11 \\
\hline+ & 7 & 7 \\
\hline$p=0.7496$ & & \\
\hline \multicolumn{3}{|c|}{ Hormone receptor PR } \\
\hline - & 9 & 1 \\
\hline+ & 10 & 15 \\
\hline \multirow{2}{*}{\multicolumn{3}{|c|}{$\begin{array}{l}\mathrm{p}=0.0098 \\
\text { Hormone receptor ER }\end{array}$}} \\
\hline & & \\
\hline- & 7 & 1 \\
\hline$\stackrel{+}{p=0.0472}$ & 12 & 15 \\
\hline
\end{tabular}

The results show an association between $3 p \mathrm{LOH}$ and increasing tumour grade, although this is not significant. There was no correlation between LOH and lymph node status. There was a significant correlation between loss of PR and ER expression (PR, $p=0.0098 ; E R, p=0.0472)$ and loss at any $3 p$ locus.

and eight of the 11 grade 3 tumours showed $3 p$ loss. Although the above figures are not significant, they do demonstrate a trend between $3 p$ loss and increasing tumour grade.

Next, we investigated whether there was an association between tumour PR and ER expression and $3 p$ allele loss. When the whole $3 \mathrm{p}$ arm was analysed we found that PR negative status was significantly more frequent in carcinomas with $\mathrm{LOH}$ at any $3 \mathrm{p}$ marker (nine of 19) than in those without $3 \mathrm{p} \mathrm{LOH}$ (one of 16) $(p=0.0098)$. A significant association was also found for ER negative status and $3 p$ loss (seven of 19) compared with tumours without $3 p$ loss (one of 16) ( $\mathrm{p}=0.0472)$ (table 1). Furthermore, we found that two of the three carcinomas (tumours 11, 17, and 19) that had only 3p21-22 loss and known receptor status had loss of PR and ER expression, whereas the remaining tumour was positive for both receptors. This suggests a correlation between 3p21-22 allele loss and lack of PR and ER expression. The presence or absence of cancer cells in the lymph nodes is an important prognostic parameter; patients with few or no positive nodes have a far better prognosis than those with many. In our series of early stage invasive breast tumours, 14 of 25 lymph node negative tumours had loss of $3 \mathrm{p}$ markers, as did seven of 14 lymph node positive tumours. Hence, there was no correlation between lymph node status and $3 p$ loss $(p=0.7496)$ (table 1).

\section{Discussion}

We undertook high resolution deletion mapping on chromosome $3 p$ in $\mathrm{T} 1 \mathrm{~N} 0$ and $\mathrm{T} 1 \mathrm{~N} 1$ invasive breast cancers to determine the frequency and importance of $3 p$ loss and to map the precise regions on $3 p$ that may contain TSGs important in breast cancer progression. We found the following: (1) a high incidence of $3 \mathrm{p}$ loss in this defined group of sporadic breast cancers; (2) evidence for two major candidate regions for $3 \mathrm{p}$ breast TSGs; (3) a trend between $3 p$ allele loss and tumour grade; and
(4) a significant correlation between $3 p$ loss and loss of PR and ER expression. Although several other studies have analysed $3 p$ LOH in breast cancer and reported $\mathrm{LOH}$ frequencies of $27-51 \%,{ }^{35-38}$ these studies included all tumour stages and did not use a high density of markers for candidate breast cancer TSG regions. We found that just over a half of early stage invasive breast tumours showed loss of one or more $3 \mathrm{p}$ markers and defined two minimal regions of loss that may contain TSGs involved in the progression of breast cancer. Within the group studied we saw a trend between $3 p \mathrm{LOH}$ and increasing tumour grade. A recent study using comparative genomic hybridisation analysis of unselected breast cancers reported higher $3 \mathrm{p}$ loss in grade 3 breast tumours than in grade 1 tumours. ${ }^{39}$ These findings suggest that there are genes on $3 p$ that are involved in the control of differentiation. Loss of these will result in the development of more aggressive cancers and this is confirmed by our finding of a significant correlation between chromosome $3 p$ allele loss (most notably 3p21-22) and lack of PR and ER.

Multiple TSGs map to chromosome $3 p$ and although we observed loss of one or more $3 p$ markers in just over a half of the tumours, no tumour showed complete $3 \mathrm{p} \mathrm{LOH}$. We found that $\mathrm{LOH}$ was most frequent at 3p21-22. This region contains the LCTSGR1 (represented by microsatellite markers D3S1568 and D3S1621), which demonstrates overlapping homozygous deletions in lung and breast tumour cell lines. ${ }^{24-27}$ Although the physical distance between the markers at borders of this region is $12 \mathrm{Mb}$, the smaller regions of overlapping allelic losses within this interval narrow the candidate region to $0.65 \mathrm{Mb}$. This region between D3S1289 and D3S2408 overlaps with one of three candidate regions for suppression of tumorigenicity of an ovarian tumour cell line (fig 1). ${ }^{110}$ Multiple genes have been isolated from LCTSGR $1,{ }^{27}$ but to date, inactivating mutations in these genes are absent or rare in human cancers. Very recently, we and others have identified a gene (RASSF1A) from LCTSGR1 at 3p21.3 that is epigenetically inactivated in most lung cancers and to a lesser extent in breast tumours. ${ }^{41-43}$

The second most frequent region of $\mathrm{LOH}$ in early breast cancer that we identified was at 3 p12. Within this region, the marker D3S1604 gave the highest loss, and the candidate interval corresponded to the LCTSGR2 region, which is defined by the presence of homozygous deletions in two lung cancer cell lines. ${ }^{28} 4445$ LCTSGR2 also contains a homozygous deletion in one breast tumour cell line and this region is cloned in a $8 \mathrm{Mb}$ yeast artificial chromosome contig. A candidate TSG, DUTT1, was isolated from this region. DUTT1 is a member of the NCAM family of genes, which includes the DCC (deleted in colorectal cancer) gene; however, DUTT1 mutations have so far not been identified in lung cancer and mutation analysis of DUTT1 in breast cancer has not been reported. ${ }^{28}{ }^{46}$ Recently, the 3 p12 region implicated in renal cell carcinoma by microcell mediated tumour suppression 
studies was shown to overlap with LCTSGR2. ${ }^{47} 48$

We also observed $3 \mathrm{p} \mathrm{LOH}$ at $3 \mathrm{p} 14.2$ and $3 \mathrm{p} 24-25$ in our panel of breast tumours. However, loss in these regions was less frequent than at $3 \mathrm{p} 21-22$ and $3 \mathrm{p} 12$, and no tumour that was informative at $3 \mathrm{p} 12$ and $3 \mathrm{p} 21$ demonstrated $\mathrm{LOH}$ at $3 \mathrm{p} 14.2$ and not $3 \mathrm{p} 12$ or $3 \mathrm{p} 21$. Similarly, 3p24-25 LOH was always seen in tumours with coexisting $3 \mathrm{p} 21-22$ or $3 \mathrm{p} 12$ LOH. The VHL TSG maps to chromosome 3 p25, but VHL gene mutations have not been identified in breast cancer. The 3p24-25 region is one of three candidate intervals for an ovarian cancer TSG; however, although a distal $3 p$ TSG may be involved in some breast cancers, other $3 \mathrm{p}$ TSGs appear to be more important. We found five breast tumours that showed allelic losses at the FHIT locus. Abnormalities of FHIT mRNA transcripts and hemizygous and homozygous allelic losses at the FHIT locus have been reported in various cancers including lung, kidney, breast, and digestive tract cancers (reviewed in Huebner and colleagues ${ }^{21}$ and Sozzi and colleagues ${ }^{22}$ ). Although the role of the FHIT gene in tumorigenesis is still controversial, our results suggest that other 3p TSGs are more important for breast tumorigenesis. The pattern of discontinuous regions of $3 \mathrm{p} \mathrm{LOH}$ with frequent losses at $3 \mathrm{p} 21-22$ and $3 \mathrm{p} 12$ is similar to that reported in lung cancer and preneoplastic lung lesions. ${ }^{129}$ The similarities between $3 p$ LOH in lung and breast cancer suggest that the relevant 3 p TSGs are involved in both tumour types.

In summary, we have demonstrated that regions on $3 p(3 p 21-22$ and $3 p 12)$ containing overlapping homozygous deletions in lung and breast tumours and tumour cell lines and a region involved in ovarian tumour suppression (3p21) show a high percentage of allelic losses in T1N0 and T1N1 invasive cancer, irrespective of node status, hence providing evidence for the involvement of genes residing at these regions in sporadic breast cancer development and progression. We also demonstrated increasing $3 p$ loss with tumour grade and loss of $\mathrm{ER}$ and PR expression, resulting in the formation of more aggressive tumours. Larger studies are required to evaluate whether the $3 p$ allelic losses described in this report can form a useful screening tool for identifying and understanding more aggressive disease.

This work was supported in part by a Breast Cancer Campaign grant, the University of Antioquia, Medellin (AM), and a fellowship from COLCIENCIAS (AM).

1 Harris JR, Lippman ME, Veronesi U, et al. Breast cancer (3). N Engl fै Med 1992;327:473-80.

2 Walker RA, Jones JL, Chappell S, et al. Molecular pathology of breast cancer and its application to clinical management Cancer Metastasis Rev 1997;16:5-27.

3 Bieche I, Lidereau R. Genetic alterations in breast cancer. Genes Chromosomes Cancer 1995;14:227-51.

4 Schwab M. Amplification of oncogenes in human cancer cells. Bioessays 1998;20:473-9.

5 Buchholz TA, Weil MM, Story MD, et al. Tumor suppressor genes and breast cancer. Radiat Oncol Invest 1999;7:55-65.

6 Yang X, Lippman ME. BRCA1 and BRCA2 in breast cancer. Breast Cancer Res Treat 1999;54:1-10.

7 Bishop DT. BRCA1, BRCA2, BRCA3 ... a myriad of breast cancer genes. Eur f Cancer 1994;30A:1738-9.

8 Seitz S, Rohde K, Bender E, et al. Strong indication for a breast cancer susceptibility gene on chromosome $8 \mathrm{p} 12-$ p22: linkage analysis in German breast cancer families. p22: linkage analysis in
Oncogene 1997; 14:741-3.
9 Kok K, Naylor SL, Buys CH. Deletions of the short arm of chromosome 3 in solid tumors and the search for suppreschromosome 3 in solid tumors and the searc
sor genes. Adv Cancer Res 1997;71:27-92.

10 Wistuba II, Montellano FD, Milchgrub S, et al. Deletions of chromosome $3 \mathrm{p}$ are frequent and early events in the pathogenesis of uterine cervical carcinoma. Cancer Res 1997;57: $3154-8$ 11 Fullwood P, Sergio M, Rader JS, et al. Detailed genetic and
physical mapping of tumor suppressor loci on chromosome 3p in ovarian cancer. Cancer Res 1999;59:4662-7.

12 Wistuba II, Behrens C, Milchgrub S, et al. Sequential molecular abnormalities are involved in the multistage development of squamous cell lung carcinoma. Oncogene 1999;18:643-50.

13 Wistuba II, Behrens C, Virmani AK, et al. High resolution chromosome $3 \mathrm{p}$ allelotyping of lung cancer and preneoplastic bronchial epithelium reveals multiple sites of $3 p$ allele loss and frequent breakpoints in the $600 \mathrm{~kb} 3 \mathrm{p} 21.3$ allele loss and frequent breakpoints in
region. Cancer Res 2000;60:1949-60.

14 Latif F, Tory K, Gnarra J, et al. Identification of the von Hippel-Lindau disease tumor suppressor gene. Science 1993;260:1317-20.

15 Kaelin WG, Jr, Maher ER. The VHL tumour-suppressor gene paradigm. Trends Genet 1998;14:423-6.

16 Foster K, Prowse A, van den Berg A, et al. Somatic mutations of the von Hippel-Lindau disease tumour suppressor gene in non-familial clear cell renal carcinoma. Hum Mol Genet 1994;3:2169-73.

17 Gnarra JR, Tory K, Weng Y, et al. Mutation of the VHL tumour suppressor gene in renal carcinoma. Nat Genet 1994;7:85-90.

18 Herman JG, Latif F, Weng Y, et al. Silencing of the VHL tumor-suppressor gene by DNA methylation in renal carcinoma. Proc Natl Acad Sci U S A 1994;91:9700-4.

19 Clifford SC, Prowse AH, Affara NA, et al. Inactivation of the von Hippel-Lindau (VHL) tumour suppressor gene and allelic losses at chromosome arm $3 \mathrm{p}$ in primary renal cell carcinoma: evidence for a VHL-independent pathway in clear cell renal tumorigenesis. Genes Chromosomes Cancer 1998;22:200-9.

20 Foster K, Osborne RJ, Huddart RA, et al. Molecular genetic analysis of the von Hippel-Lindau disease (VHL) tumour suppressor gene in gonadal tumors. Eur $\mathcal{f}$ Cancer 1995;31A:2392-5.

21 Huebner K, Garrison PN, Barnes LD, et al. The role of the FHIT/FRA3B locus in cancer. Annu Rev Genet 1998;32:731.

22 Sozzi G, Huebner K, Croce CM. FHIT in human cancer. Adv Cancer Res 1998;74:141-66.

23 Man S, Ellis IO, Sibbering M, et al. High levels of allele loss at the FHIT and ATM genes in non-comedo ductal carcinoma in situ and grade I tubular invasive breast cancers. Cancer Res 1996;56:5484-9.

24 Daly MC, Xiang RH, Buchhagen D, et al. A homozygous deletion on chromosome 3 in a small cell lung cancer cell line correlates with a region of tumor suppressor activity. Oncogene 1993;8:1721-9.

25 Wei MH, Latif F, Bader S, et al. Construction of a $600 \mathrm{~kb}$ cosmid clone contig and generation of a transcriptional map surrounding the lung cancer tumour suppressor gene (TSG) locus on human chromosome $3 \mathrm{p} 21.3$. Cancer Res 1996;56:1487-92.

26 Sekido Y, Ahmadian M, Wistuba II, et al. Cloning of a breast cancer homozygous deletion junction narrows the region of search for a 3p21.3 tumor suppressor gene. Oncogene 1998; 16:3151-7.

27 Lerman MI, Minna JD, for The International Lung Cancer Chromosome 3p21.3 Tumor Suppressor Gene Consortium. The $630 \mathrm{~kb}$ lung cancer homozygous deletion region on human chromosome $3 \mathrm{p} 21.3$ : identification and evaluation of the resident candidate tumor suppressor genes. Cancer Res 2000;60:6116-33.

28 Sundaresan V, Chung G, Heppell-Parton A, et al. Homozygous deletions at $3 \mathrm{p} 12$ in breast and lung cancer. Zygous deletions at 3p12

29 Euhus DM, Maitra A, Wistuba II, et al. Loss of heterozygosity at $3 \mathrm{p}$ in benign lesions preceding invasive breast cancer. F Surg Res 1999;83:13-18.

30 Deng G, Lu Y, Zlotnikov G, et al. Loss of heterozygosity in normal tissue adjacent to breast carcinomas. Science 1996; 274:2057-9.

31 Buerger H, Otterbach F, Simon R, et al. Comparative genomic hybidization of ductal carcinoma in situ of the breast-evidence of multiple genetic pathways. F Pathol 1999;187:396-402.

32 Elston CW, Ellis IO. Pathological prognostic factors in breast cancer. I. The value of histological grade in breast cancer: experience from a large study with long-term cancer: experience from a large study
follow-up. Histopathology 1991;19:403-10.

33 Chappell SA, Walsh T, Walker RA, et al. Loss of heterozygosity at chromosome $6 \mathrm{q}$ in preinvasive and early invasive breast carcinomas. Br f Cancer 1997;75:1324-9.

34 Shaw JA, Walsh T, Chappell SA, et al. Microsatellite instability in early sporadic breast cancer. $\mathrm{Br} \mathcal{F}$ Cancer 1996;73:1393-7.

35 Ali IU, Lidereau R, Callahan R. Presence of two members of c-erbA receptor gene family (c-erbA beta and c-erbA2) in smallest region of somatic homozygosity on chromosome 3p21-p25 in human breast carcinoma. 7 Natl Cancer Inst 1989;81:1815-20.

36 Sato T, Akiyama F, Sakamoto G, et al. Accumulation of genetic alterations and progression of primary breast
cancer. Cancer Res 1991;51:5794-9. 
37 Matsumoto S, Kasumi F, Sakamoto G, et al. Detailed deletion mapping of chromosome arm $3 \mathrm{p}$ in breast cancers: $2-\mathrm{cM}$ region on $3 \mathrm{p} 14.3-21.1$ and a 5 -cM region on 3p24.3-25.1 commonly deleted in tumors. Genes Chromosomes Cancer 1997;20:268-74.

38 Braga E, Pugacheva E, Bazov I, et al. Comparative allelotyping of the short arm of human chromosome 3 in epithelial tumors of four different types. FEBS Lett 1999;454:215-19.

39 Roylance R, Gorman P, Harris W, et al. Comparative genomic hybridization of breast tumors stratified by histological grade reveals new insights into the biological

progression of breast cancer. Cancer Res 1999;59:1433-6.

0 Rimessi P, Gualandi F, Morelli C, et al. Transfer of human chromosome 3 to an ovarian carcinoma cell line identifie three regions on $3 p$ involved in ovarian cancer. Oncogene 1994;9:3467-74

41 Dammann $\mathrm{R}, \mathrm{Li} \mathrm{C}$, Yoon JH, et al. Epigenetic inactivation of a RAS association domain family protein from the lung a RAS association domain family protein from the lung
tumour suppressor locus 3p21.3. Nat Genet 2000;25:31519 .

42 Burbee DG, Forgacs E, Zochbauer S, et al. The RASSF1A locus in the $3 \mathrm{p} 21.3$ homozygous deletion region: epigenetic in the malignant phenotype. F Natl Cancer Inst 2001;93:6919

43 Agathanggelou A, Honorio S, Macartney DP, et al. Methylation associated inactivation of RASSF1A from region 3 p21.3 in lung, breast and ovarian tumors. Oncogene $2001 ; 20: 1509-18$.
44 Rabbitts P, Bergh J, Douglas J, et al. A submicroscopic homozygous deletion at the D3S3 locus in a cell line isolated from a small cell lung carcinoma. Genes Chromosomes Cancer 1990;2:231-8.

45 Latif F, Tory K, Modi W, et al. Molecular characterization of a large homozygous deletion in the small cell lung cancer line U2020: a strategy for cloning the putative tumor suppressor gene. Genes Chromosomes Cancer 1992;5:11927.

46 Sundaresan V, Roberts I, Bateman A, et al. The DUTT1 gene, a novel NCAM family member is expressed in developing murine neural tissues and has an unusually broad pattern of expression. Mol Cell Neurosci 1998;11:2935.

47 Lott ST, Lovell M, Naylor SL, et al. Physical and functional mapping of a tumor suppressor locus for renal cell carcinoma within chromosome 3p12. Cancer Res 1998;58: 3533-7.

48 Lovell M, Lott ST, Wong P, et al. The genetic locus NRC-1 within chromosome $3 \mathrm{p} 12$ mediates tumor suppression in renal cell carcinoma independently of histological type, tumor microenvironment, and VHL mutation. Cancer Res 1999;59:2182-9.

49 Sundaresan V, Ganly P, Hasleton P, et al. p53 and chromosome 3 abnormalities, characteristic of malignant lung tumours, are detectable in preinvasive lesions of the bronchus. Oncogene 1992;7:1989-97. 